\title{
Intervenção psicoterápica de grupo com pais e bebês: relato de um caso
}

\author{
Psychotherapeutic group intervention for parents and infants: a case report
}

\author{
Fernanda Caldas Jardim¹, Maria Lucrécia Zavaschi², Flávia Costa ${ }^{3}$, Solanger Perrone, Cristian \\ Patrick Zeni ${ }^{5}$
}

${ }^{1}$ Psicóloga. ${ }^{2}$ Psiquiatra psicanalista. Professora adjunta, Departamento de Psiquiatria e Medicina, Universidade Federal do Rio Grande do Sul (UFRGS), Porto Alegre, RS. Membro efetivo, Sociedade Psicanalítica de Porto Alegre (SPPA), Porto Alegre, RS. ${ }^{3}$ Psiquiatra. Professora convidada, Departamento de Psiquiatria e Medicina Legal, UFRGS. ${ }^{4}$ Enfermeira, Ambulatório de Puericultura, Hospital de Clínicas de Porto Alegre (HCPA), Porto Alegre, RS. ${ }^{5}$ Médico psiquiatra. Mestre em psiquiatria, UFRGS. Doutorando em Psiquiatria, UFRGS.

\section{Resumo}

Objetivos: Demonstrar a eficácia de uma intervenção psicoterápica em grupo (grupo operativo de reflexão) onde pais e bebês são atendidos concomitantemente.

Metodologia: Através do relato de caso de uma menina com quadro de crises de agressividade, são discutidos aspectos da intervenção psicoterápica.

Resultados: Houve resolução dos sintomas, e aspectos saudáveis da interação mãe-bebê foram restabelecidos.

Discussão: No caso apresentado, o grupo operativo de reflexão foi fundamental para a melhora dos problemas apresentados por uma dupla mãe-bebê, auxiliando a mãe e o bebê a modificar aspectos disfuncionais na sua interação.

Conclusões: Apesar dos bons resultados para essa família, mais estudos são necessários para avaliar o efeito do grupo operativo de reflexão.

Descritores: Intervenção psicoterápica, grupoterapia, relação pais/bebê.

\section{Abstract}

Objectives: To demonstrate the efficacy of a psychotherapeutic group intervention (reflective operational group), in which parents and infants are seen concomitantly.

Methods: In a case report of a female infant who presented aggressiveness, aspects of the psychotherapeutic intervention are discussed.

Results: There was resolution of symptoms, and healthy aspects of the mother-infant interaction were reestablished.

Discussion: In the reported case, the reflective operational group was fundamental to symptom improvement presented by a mother-infant dyad, helping the mother and the baby change dysfunctional aspects of their interaction.

Conclusions: In spite of the good results for this family, further studies are needed to assess the efficacy of the reflective operational group.

Keywords: Psychotherapeutic intervention, group therapy, parent-infant relationship.

\section{Introdução}

Com base em resultados de estudos que identificam fatores psicossociais, biológicos e afetivos que exercem influência sobre o desenvolvimento infantil e no reconhecimento de que os fundamentos do psiquismo são construídos nos três primeiros anos de vida, a partir das experiências vivenciadas pelos bebês e seus pais, foram 
desenvolvidos métodos psicoterápicos de intervenção, com vistas à prevenção de problemas mentais ${ }^{1-5}$. Esse tipo de atendimento é realizado com a presença do bebê, junto aos pais, na situação terapêutica ${ }^{6-8}$.

No Ambulatório de Interação Pais-Bebê do Hospital de Clínicas de Porto Alegre (HCPA), utiliza-se a técnica do grupo operativo de reflexão, que proporciona troca de experiências entre os membros do grupo, além de um interjogo de identificações que facilita a comunicação dos problemas e a posterior resolução dos conflitos ${ }^{9}$.

Os encontros são semanais, com 1 hora e meia de duração. No setting, os pais e os profissionais sentamse em forma de círculo, e as crianças ficam no centro, tendo à disposição uma caixa contendo brinquedos adequados à faixa etária. A partir de situações trazidas pelos participantes, ocorre um processo de reflexão grupal que proporciona mudanças de atitudes dos pais com relação às condutas que possam envolver risco ao desenvolvimento da criança.

O grupo é indicado para as famílias que apresentam problemas na relação com a criança ( 0 a 3 anos) que possam acarretar riscos ao desenvolvimento da mesma.

O presente caso clínico visa relatar modificações na relação pais-bebê e no desenvolvimento a partir de um atendimento em grupo. Tomamos o cuidado de preservar o anonimato dos pacientes através de alterações nos dados de identificação.

\section{Apresentação do caso}

J. é filha única, fruto de uma relação extraconjugal do pai. Foi encaminhada para o Grupo de Interação PaisBebê do HCPA com 1 ano e 3 meses por queixa da mãe de não conseguir lidar com as crises de brabeza da filha e por queixa da creche de que a menina estava mordendo os colegas.

A mãe de J. tem 36 anos e ensino médio completo. Nasceu de um relacionamento de sua mãe com um colega de aula, que não assumiu a paternidade. O pai de J. tem 55 anos, é proprietário de uma videolocadora, casado e pai de outros três filhos. Nunca compareceu ao grupo. Conheceram-se quando a mãe trabalhava como secretária do pai. Iniciaram um relacionamento, que resultou na gestação e nascimento de J. A gestação foi considerada de risco, tendo acompanhamento médico regular. J. nasceu de parto normal. Foi encaminhada à puericultura no primeiro mês de vida, devido às dificuldades da mãe em lidar com o choro forte e com a agitação da menina durante a amamentação. Dormia na cama com a mãe, e isso se manteve até os 2 anos de idade.

Aos 3 meses, houve uma tentativa frustrada de alimentá-la com leite artificial. Com 1 ano, recusava alimentação salgada e exigia o seio, inclusive de madrugada. O desmame só ocorreu definitivamente em torno dos 3 anos. Entrou na creche com 1 ano de idade e logo apresentou o comportamento de morder os colegas.

Mãe e filha ingressaram no Grupo de Interação PaisBebê no seu quinto dia de funcionamento e sempre foram assíduas e pontuais.

J. é uma menina pequena, delicada e graciosa. Apresentava-se sempre bem vestida e enfeitada. No início do grupo, permanecia todo o tempo no colo da mãe. Algumas vezes pedia o seio, e quando negado, agitava-se, esperneava, chorava, e a mãe não conseguia controlá-la. Várias vezes, mordia as outras crianças, a mãe e até os profissionais.

A mãe queixava-se de não conseguir dar limites e nem dizer não para a filha, que só comia o que queria, só fazia o que estava com vontade, chorava para conseguir as coisas, escolhia o que vestir, era teimosa, estava mordendo as pessoas e não podia ser contrariada. A hora do banho era "uma tortura", pois J. levava para o chuveiro seus brinquedos e permanecia ali, brincando, e a mãe não conseguia convencê-la a sair. Dizia sentir-se cedendo aos desejos da filha e já estar revidando de forma agressiva.

O pai não morava com elas, mas as visitava diariamente. Toda vez que saía, dizia que ia trabalhar, fazendo com que, segundo a mãe, J. não percebesse que o pai tinha outra família.

Com o decorrer do atendimento, J. deixou de ficar no colo da mãe e conseguia brincar com as outras crianças. Aprendeu a dividir os brinquedos ou trocá-los ao invés de arrancá-los da mão de alguém, mas sua oralidade continuava intensa. Mordia todas as crianças, principalmente quando deixava de ser o centro das atenções.

A entrada de R., 4 meses, no grupo, foi marcada por uma intensa agitação e agressividade de J. Tentou mordê-lo inúmeras vezes e fez de tudo para chamar a atenção da mãe, atirando-se no chão, jogando os brinquedos longe, mordendo e arrancando os brinquedos de outras crianças. Teve que ser contida muitas vezes.

Através da reflexão sobre situações trazidas pelos participantes do grupo e de intervenções realizadas pelos profissionais, que serviram como um modelo positivo, a mãe foi se fortalecendo e mostrando-se mais firme no manejo com a filha. Aprendeu a olhar nos olhos, dizer não, ser firme sem ser agressiva e não se deixar levar pelo choro da menina. A professora da creche estava surpresa com a mudança positiva.

J. já brincava com as outras crianças e dividia os brinquedos. A mãe relata que, durante esse período, conseguiu lidar melhor com as dificuldades. Conseguiu expressar sentimentos em relação à mentira contada sobre a ausência do pai, assunto que antes não reconhecia estar errado, manifestando o desejo de restabelecer a verdade. 
Depois de 1 ano e 8 meses de funcionamento, os encontros estavam terminando. Nesse período, reproduzindo as reações comuns de pacientes em psicoterapia diante da proximidade da alta, a mãe faltou a vários encontros do grupo, em contraste com sua assiduidade anterior. J., por sua vez, apresentou por curto período sintomas presentes no início do atendimento, mordendo uma outra menina de 6 meses.

\section{Discussão}

No presente caso clínico, chama a atenção a sua evolução. Quando essa dupla ingressou no grupo, a mãe estava identificada com os sentimentos primitivos da filha e era incapaz de dar-lhe limites e oferecer continência. Com isso, acabava cedendo às suas exigências mais regressivas, caracterizadas por uma voracidade incontrolável e reagindo depois de forma agressiva.

Acredita-se que os aspectos narcisistas da mãe, projetados na filha, dificultaram sua percepção quanto aos erros e fracassos na educação de J. Negava a realidade, tentando manter um mundo fantasioso para que a filha não passasse por frustrações. Foi buscando essa "perfeição" que se tornou incapaz de decodificar suas reais necessidades.

Pode-se pensar que a amamentação prolongada estava a serviço de uma satisfação erotizada da mãe e sem conotação nutritiva, como um objeto substituto dos seus sentimentos de vazio.

Acerca do pai, novamente a mãe estava preservando sua fantasia de "perfeição". Ao escolher um homem mais velho (possível representação do pai), que já tinha uma família e era casado, acaba repetindo a história de sua mãe, que teve uma filha com um homem que não assumiu a gravidez e não foi presente em sua vida.

A mãe foi se dando conta das suas dificuldades e conseguiu restaurar a verdade sobre o pai de J. Também conseguiu liberá-la de suas projeções, que estavam ocorrendo em uma etapa muito importante do desenvolvimento. Iniciou o processo de desmame e, nesse momento, J., com quase 3 anos de idade, exacerbou seus aspectos primitivos, mordendo as pessoas e introduzindo a mão e objetos na boca. A mãe soube contê-la com atenção, conversas, carinhos e brincadeiras. Estabeleceram um bom vínculo e uma relação confiável, e aos poucos a menina já estava brincando com as outras crianças e deixou de morder. A mãe foi encaminhada para psicoterapia e segue em atendimento individual.

A técnica utilizada no atendimento do caso, o grupo operativo de reflexão, proporciona a comunicação das dúvidas e problemas, a troca de experiências, a reflexão sobre os assuntos e a posterior resolução dos conflitos, que facilitam as mudanças de atitudes internas dos membros do grupo. Tem como foco o desenvolvimento do bebê e o vínculo com seus pais.

Os bons resultados obtidos com a dupla em questão e com outras famílias que participaram da experiência mostram-nos a relevância dessa intervenção terapêutica e encorajam-nos a prosseguir estudando e pesquisando, por julgarmos que essa técnica possa beneficiar mais famílias. Embora esta seja uma experiência inicial, que nos anima pelos bons resultados clínicos obtidos com esse grupo, vemos a necessidade de mais estudos em extensão e profundidade.

\section{Referências}

1. Spitz RA. O primeiro ano de vida: um estudo psicanalítico do desenvolvimento normal e anômalo das relações objetais. São Paulo: Martins Fontes; 1980.

2. Acquarone S. Psychotherapeutic interventions in cases of impaired mother/infant relationships. J Child Psychother. 1987; 13(2):4563.

3. Osofsky JD, editor. Handbook of infant development. 2nd ed. New York: John Wiley \& Sons; 1987.

4. Stern DN. O mundo interpessoal do bebê: uma visão a partir da psicanálise e da psicologia do desenvolvimento. Porto Alegre: Artmed; 1992.

5. Zavaschi MLS. Associação entre depressão na vida adulta a trauma psicológico na infância [dissertação]. Porto Alegre: UFRGS; 2003.

6. Fraiberg S, editor. Clinical studies in infant mental health: the first year of life. London: Tavistock; 1980.

7. Zeanah $\mathrm{CH}$, Boris NW, Larrieu JA. Infant development and developmental risk: a review of the past 10 years. J Am Acad Child Adolesc Psychiatry. 1997;36(2):165-78.

8. Cramer B. Profissão bebê. Martins Fontes: São Paulo; 1993.

9. Zimerman DE. Fundamentos básicos das grupoterapias. 2. ed. Porto Alegre: Artmed; 2000. 